\title{
Patient understanding regarding opioid use in an orthopaedic trauma surgery population: a survey study
}

Amy L. Xu', Alexandra M. Dunham', Zachary O. Enumah² and Casey J. Humbyrd ${ }^{3 *}$ (D)

\begin{abstract}
Background: Prior studies have assessed provider knowledge and factors associated with opioid misuse; similar studies evaluating patient knowledge are lacking. The purpose of this study was to assess the degree of understanding regarding opioid use in orthopaedic trauma patients. We also sought to determine the demographic factors and clinical and personal experiences associated with level of understanding.

Methods: One hundred and sixty-six adult orthopaedic trauma surgery patients across two clinical sites of an academic institution participated in an internet-based survey (2352 invited, 7.1\% response rate). Demographic, clinical, and personal experience variables, as well as perceptions surrounding opioid use were collected. Relationships between patient characteristics and opioid perceptions were identified using univariate and multivariable logistic regressions. Alpha $=0.05$.
\end{abstract}

Results: Excellent recognition (> $85 \%$ correct) of common opioids, side effects, withdrawal symptoms, and disposal methods was demonstrated by $29 \%, 10 \%, 30 \%$, and $2.4 \%$ of patients; poor recognition ( $<55 \%)$ by $11 \%, 56 \%, 33 \%$, and $52 \%$ of patients, respectively. Compared with white patients, non-white patients had 7.8 times greater odds (95\% confidence interval [CI 1.9-31) of perceiving addiction discrepancy $(p=0.004)$. Employed patients with higher education levels were less likely to have excellent understanding of side effects (adjusted odds ratio [aOR] 0.06, 95\% $\mathrm{Cl} 0.006-0.56 ; p=0.01$ ) and to understand that dependence can occur within 2 weeks (aOR $0.28,95 \% \mathrm{Cl} 0.09-0.86$; $p=0.03)$ than unemployed patients. Patients in the second least disadvantaged ADI quartile were more knowledgeable about side effects (aOR 8.8, 95\% Cl 1.7-46) and withdrawal symptoms (aOR 2.7, 95\% Cl 1.0-7.2; $p=0.046$ ) than those in the least disadvantaged quartile. Patients who knew someone who was dependent or overdosed on opioids were less likely to perceive addiction discrepancy (aOR $0.24,95 \% \mathrm{Cl} 0.07-0.76 ; p=0.02$ ) as well as more likely to have excellent knowledge of withdrawal symptoms (aOR $2.6,95 \% \mathrm{Cl}$ 1.1-6.5, $p=0.03$ ) and to understand that dependence can develop within 2 weeks (aOR 3.8, 95\% Cl 1.5-9.8, $p=0.005$ ).

Conclusions: Level of understanding regarding opioid use is low among orthopaedic trauma surgery patients. Clinical and personal experiences with opioids, in addition to demographics, should be emphasized in the clinical history.

Keywords: Opioid misuse, Patient knowledge, Addiction, Dependence, Naloxone

\footnotetext{
*Correspondence: casey.humbyrd@pennmedicine.upenn.edu

${ }^{3}$ Department of Orthopaedic Surgery, The University of Pennsylvania, 230

West Washington Square, 5th Floor Farm Journal Building,"Philadelphia, PA 19106, USA

Full list of author information is available at the end of the article
}

\section{Background}

The United States has been in the midst of a public health crisis-nearly $70 \%$ of the 67,367 drug overdose deaths in 2018 reported involvement of an opioid [1]. Prescription opioid misuse is a recognized patient safety issue within the medical community. Because 
many patients are first exposed to opioids after undergoing a surgery and surgeons are amongst the highest prescribers of opioids [2,3], there has been a push within surgical specialties to educate physicians and their patients on the appropriate use of opioids. These efforts have largely targeted prescribing practices to reduce prescription size without increasing the need for refills due to poor pain management $[4,5]$. The Centers for Disease Control suggest early successes from such efforts, estimating a $17 \%$ decrease in prescription opioid-involved death rates from 2017 to 2019 [1]. However, recent data demonstrate an increase in overall overdose deaths coinciding with the start of the coronavirus disease (COVID-19) pandemic with over 81,000 deaths occurring in the year ending in May 2020 [6].

While there is some improvement in prescription opioid-related deaths, long-term use of opioids after surgery remains high [2, 3]. To aid surgeons in understanding patients' risk of chronically using opioids, previous studies have assessed factors that may predispose individuals to opioid abuse after procedures $[7,8]$. These studies have suggested younger age, female sex, lower income, and specific medical comorbidities (i.e. pre-surgical opioid use, history of substance abuse, and mental health factors) can predispose patients to prolonged opioid use [912]. Knowledge of appropriate opioid use is also likely to play a role. Most literature addressing opioid knowledge has focused on providers' understanding [13-15]. However, the level of patient understanding regarding opioids and their appropriate use has been minimally studied [16-19]. Specifically, opioid knowledge within the orthopaedic trauma patient population, one of the populations most at risk for opioid misuse [10], has not previously been studied.

A study within an orthopaedic hand surgery specialty practice revealed that while $80 \%$ of patients are aware of the addictive properties of opioids, a substantial proportion also possess inaccurate beliefs, such as believing that opioids work well for controlling long-term pain [20]. Given the evidence of existing knowledge gaps, it is essential to identify the specific shortcomings in patient knowledge and to determine what demographic, clinical, or personal experience factors may be associated with misconceptions of opioid use. This information will provide a foundation on which to base future educational interventions.

We therefore sought to assess the degree of understanding regarding opioid use in a consecutive sample of orthopaedic trauma patients and identify knowledge gaps. We also aimed to determine the demographic, clinical, and personal experience factors associated with level of understanding.

\section{Methods}

\section{Study design and settings}

After institutional review board approval, participants were recruited from orthopaedic surgery trauma clinics at two hospital-based clinical sites within our institution. A consecutive sample of all adult patients ( $\geq 18$ years) who visited the identified clinics between August 2009 and November 2020 were invited to participate via an email from the electronic medical record. Informed consent was obtained prior to administering an anonymous 32-question, voluntary online survey with a 7.4 grade Flesch-Kincaid reading level ("Appendix") [21, 22]. The survey was created using Qualtrics XM (Seattle, WA, USA) and distributed via the MyChart system (Epic Systems Corporation, Verona, WI) to patients meeting our inclusion criteria, 2352 of whom opened the message. The study was performed using the MyChart system, rather than in-person surveys, due to restrictions on in-person research related to the COVID-19 pandemic.

The survey included questions about the following demographic variables: gender, age, race/ethnicity, insurance status, education level, employment status, marital status, and zip code to assess area deprivation index (ADI) quartile [23]. Participants were also asked to answer questions regarding clinical and personal experience with opioid use: chronicity of the injury/ accident/problem prompting the clinic visit; whether they underwent surgery; whether they received pain medication prescription, opioid prescription, opioid disposal instructions, or naloxone prescription; whether they were currently using opioids at the time of response, and whether they personally knew someone who has been dependent or overdosed on opioids.

\section{Study population}

Seven percent of patients who opened the message (166 of 2352) completed the survey. Sixty-seven percent of the respondents (111 of 166) identified as female, $31 \%$ (52) identified as male, and 2\% (3) preferred to not provide their gender (Table 1 ).

Ninety-four percent of respondents (156) received prior opioid prescription, 10\% (16) prior naloxone prescription, and $11 \%$ (18) were currently using an opioid. Fifty percent of respondents (84) reported personally knowing someone who has been dependent on opioids, with 19\% (16 of 84 ) reporting self-dependency. Twentynine percent of respondents (48) reported knowing someone who had overdosed on opioids, with $4 \%$ (2 of 48) reporting self-overdose. Six percent of patients (10) reported knowing both (Table 1). 
Table 1 Characteristics of 166 patients presenting to orthopaedic trauma surgery clinics

\begin{tabular}{ll}
\hline Patient characteristics & \\
\hline Characteristics & $\begin{array}{l}\text { No. of } \\
\text { respondents }\end{array} \%^{\mathrm{a}}$ \\
\hline
\end{tabular}

Demographics

Gender

Female

Male

No answer

Age (yrs)

18-24

25-34

35-44

45-54

55-64

65-74

75-84

$85+$

No answer

Race/ethnicity

White

African American

Asian

Hispanic/Latino

Other

No answer

Insurance status

Insured

Not insured

No answer

Highest education level

High school or less

some college

2-year degree

4-year degree

Graduate school or higher

No answer

Employment status

Full-time

Part-time

Unemployed

Retired

Disabled

Student

No answer

Marital status

Married

Never married

Divorced

Widowed

No answer

renondents

Table 1 (continued)

\section{Patient characteristics}

\begin{tabular}{lll}
\hline Characteristics & $\begin{array}{l}\text { No. of } \\
\text { respondents }\end{array}$ & $\%^{\mathbf{a}}$ \\
\hline ADI national quartile & & \\
1 & 60 & 36 \\
2 & 51 & 31 \\
3 & 27 & 16 \\
4 & 8 & 4.8 \\
No answer & 20 & 12
\end{tabular}

Clinical and personal experiences

Reason for visit

Acute injury/accident/problem <2 weeks $\quad 13 \quad 7.8$

Subacute injury/accident/problem $>2$ weeks $\quad 94 \quad 57$

Chronic problem $\geq 1$ year $\quad 34 \quad 20$

No answer

$25 \quad 15$

Prior surgery

Yes

No

No answer

Prior pain prescription

Yes

No

No answer

Prior opioid prescription

Yes

No

No answer

$153 \quad 92$

$12 \quad 7.2$

$1 \quad 0.6$

16499

$\begin{array}{ll}1 & 0.6\end{array}$

$1 \quad 0.6$

$156 \quad 94$

$\begin{array}{ll}4 & 2.4\end{array}$

63.6

Current opioid use

Yes $18-11$

No $\quad 138 \quad 83$

No answer $\quad 10 \quad 6.0$

Prior receipt of opioid disposal instructions

Yes $\quad 5$

No

No answer

$117 \quad 70$

$44 \quad 27$

Prior naloxone prescription

Yes

$16 \quad 9.6$

No

No answer

Know person-dependent

Self

Family

Friend

Colleague

Client/student/patient/etc.

None

No answer

$16 \quad 9.6$

$27 \quad 16$

$35 \quad 21$

$2 \quad 1.2$

42.4

$81 \quad 49$

$1 \quad 0.6$

Know person-overdose

Self

2

1.2

Family

12

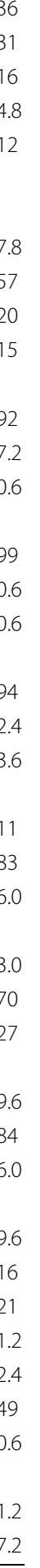


Table 1 (continued)

\begin{tabular}{lll}
\hline Patient characteristics & & \\
\hline Characteristics & $\begin{array}{l}\text { No. of } \\
\text { respondents }\end{array}$ & $\%^{\mathrm{a}}$ \\
\hline Friend & 27 & 16 \\
Colleague & 3 & 1.8 \\
Client/student/patient/etc. & 4 & 2.4 \\
None & 117 & 70 \\
No answer & 1 & 0.6 \\
\hline
\end{tabular}

$A D I$, Area deprivation index

${ }^{\text {a }}$ Percentages may not add to 100 from rounding error

\section{Primary and secondary outcomes}

Our primary study outcome was to assess trauma patients' understanding of opioid use. We defined understanding as correct identification and recognition of common opioids, suboxone/subutex, side effects, withdrawal symptoms, and appropriate disposal methods. Secondary outcomes were beliefs regarding time to dependency, safety of using over the counter (OTC) pain medications with opioids, comfort using naloxone, subjective pain level requiring opioid use, harmful effects of opioids, and confidence in their knowledge to safely manage opioid use. We also assessed addiction perception (whether others versus self can become addicted), with a discrepancy meaning they believe that others but not self can become addicted.

\section{Statistical analysis}

Survey data were analysed using descriptive statistics. Associations between demographics and clinical or personal experiences with variables assessing opioid understanding were explored using univariate and multivariable logistic regression (Additional file 1: Table S1, Table 3). The following potential confounders were included in the adjusted model: gender, age, race, marital status, employment status stratified by education level, ADI quartile, injury chronicity, prior opioid prescription, current opioid use, prior naloxone prescription, and knowing someone who has been dependent or addicted on opioids. Analyses were performed using Stata, version 16.0, software (StataCorp LLC, College Station, TX). Alpha was set at 0.05 .

\section{Results}

\section{Current level of patient understanding regarding opioid} use

Excellent recognition was defined as $>85 \%$, poor as $<55 \%$ items identified correctly. Twenty-nine percent of patients (48 of 166) demonstrated excellent recognition of common opioids. Ten percent (17) had excellent recognition of side effects, 30\% (50) withdrawal symptoms, and $2.4 \%$ (4) appropriate disposal methods. While $11 \%$ of patients (18) had poor recognition of common opioids, $56 \%$ (93), 33\% (54), and 52\% (86) poorly recognized side effects, withdrawal symptoms, and disposal methods, respectively (Fig. 1). Further, 34\% (56) believed dependence takes weeks to months to develop, and $18 \%$

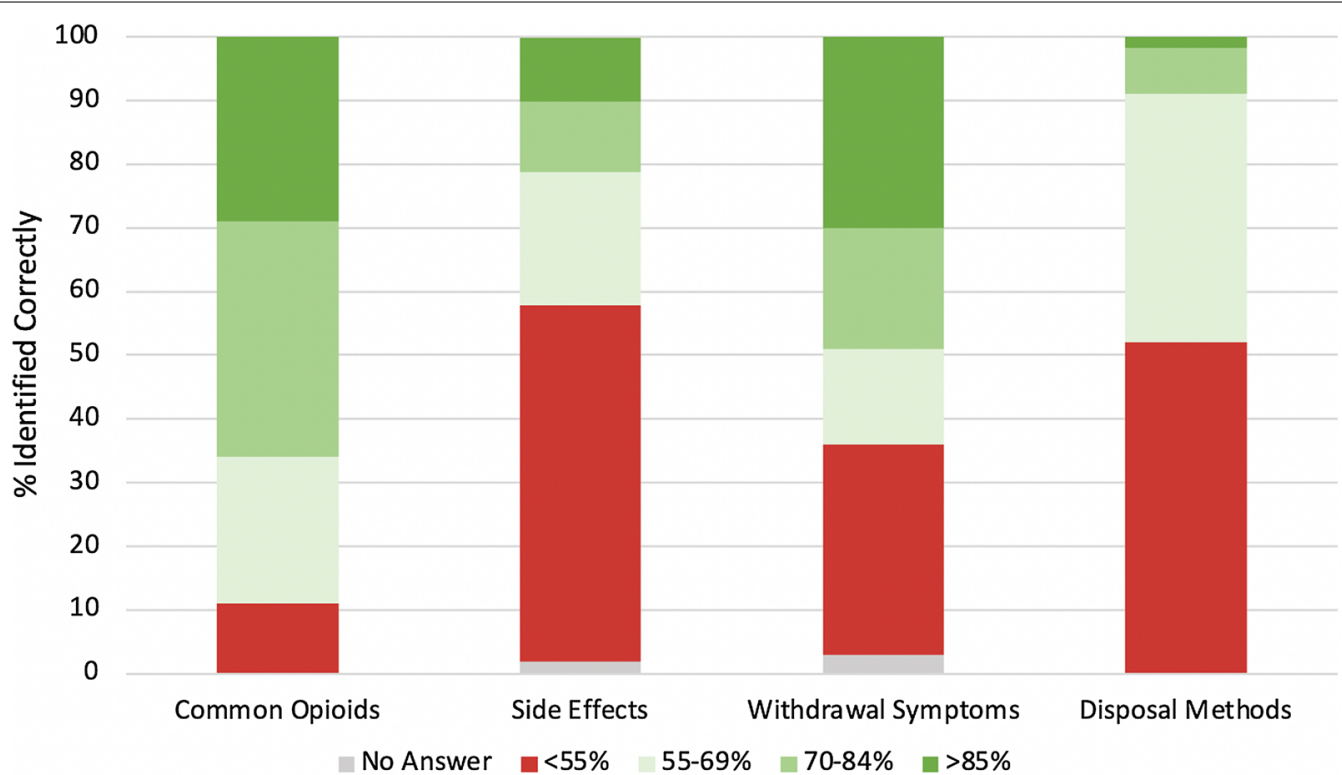

Fig. 1 Common opioids, side effects, withdrawal symptoms, and disposal methods identified correctly by orthopaedic trauma patients 
(30) were uncomfortable using naloxone. While patients almost unanimously understood that opioids are harmful and that others can become addicted, 11\% (19) had a discrepancy in addiction perception. Almost all patients $(88 \%)$ stated that they would only take an opioid for moderate to severe pain, defined as a score $\geq 5 / 10$ on the visual analog scale. Eighty-six percent of patients (143) believed they currently know enough to take opioids safely (Table 2).

\section{Demographics associated with level of understanding}

Compared with white patients, non-white patients had 7.8 times greater odds (95\% confidence interval [CI] 1.931 ) of signifying a discrepancy in addiction perception $(p=0.004)$. Employment status stratified by education level was also independently associated with knowledge of side effects. Employed patients with the highest education level were less knowledgeable about side effects (adjusted odds ratio [aOR] 0.06, 95\% CI 0.006-0.56; $p=0.01$ ) and less likely to understand that dependence can occur within 2 weeks of beginning opioids (aOR $0.28,95 \%$ CI $0.09-0.86 ; p=0.03$ ) than patients who were unemployed. After adjusting for potential confounders, patients in the second least disadvantaged ADI quartile were more knowledgeable about side effects (aOR 8.8, 95\% CI 1.7-46) and withdrawal symptoms (aOR 2.7, 95\% CI $1.0-7.2 ; p=0.046)$ than those in the least disadvantaged quartile. No other demographics were significantly associated with level of patient understanding (Table 3).

\section{Clinical and personal experiences associated with level of understanding}

Patients currently using opioids had 5.2 times greater odds (95\% CI 1.0-27) of understanding that it is safe to take opioids with OTC pain medications $(p=0.046)$. Patients who knew someone who was dependent or overdosed on opioids were significantly less likely to believe that others but not self can become addicted (aOR 0.24, 95\% CI 0.07-0.76; $p=0.02$ ). They also possessed greater knowledge regarding withdrawal symptoms (aOR 2.6, $95 \%$ CI 1.1-6.5, $p=0.03$ ) and were more likely to understand that dependence can develop within 2 weeks of initiating opioids (aOR 3.8, 95\% CI 1.5-9.8, $p=0.005$ ). No other clinical or personal experiences were significantly associated with level of patient understanding (Table 3).

\section{Discussion}

The safe prescribing of opioids is a critical issue in medicine and especially for orthopaedic trauma surgery. It is crucial to understand and improve the level of patient understanding regarding the use of opioids to improve our care of patients.
Table 2 Understanding regarding opioid use of 166 patients presenting to orthopaedic trauma surgery clinics

\begin{tabular}{|c|c|c|}
\hline \multicolumn{3}{|c|}{ Patient understanding regarding opioid use } \\
\hline Responses & $\begin{array}{l}\text { No. of } \\
\text { respondents }\end{array}$ & $\%^{\mathrm{a}}$ \\
\hline \multicolumn{3}{|l|}{ 1. Identification of opioids } \\
\hline $85 \%+$ correct & 48 & 29 \\
\hline $70-84 \%$ & 62 & 37 \\
\hline $55-69 \%$ & 38 & 23 \\
\hline$<55 \%$ & 18 & 11 \\
\hline No answer & 0 & 0.0 \\
\hline \multicolumn{3}{|c|}{ 2. Identification of suboxone/subutex } \\
\hline Both & 24 & 14 \\
\hline One & 26 & 16 \\
\hline Neither & 116 & 70 \\
\hline No answer & 0 & 0.0 \\
\hline \multicolumn{3}{|l|}{ 3. Identification of side effects } \\
\hline $85 \%+$ correct & 17 & 10 \\
\hline $70-84 \%$ & 18 & 11 \\
\hline $55-69 \%$ & 35 & 21 \\
\hline$<55 \%$ & 93 & 56 \\
\hline No answer & 3 & 1.8 \\
\hline \multicolumn{3}{|c|}{ 4. Identification of withdrawal symptoms } \\
\hline $85 \%+$ correct & 50 & 30 \\
\hline $70-84 \%$ & 32 & 19 \\
\hline $55-69 \%$ & 25 & 15 \\
\hline$<55 \%$ & 54 & 33 \\
\hline No answer & 5 & 3.0 \\
\hline \multicolumn{3}{|c|}{ 5. Identification of appropriate disposal methods } \\
\hline $85 \%+$ correct & 4 & 2.4 \\
\hline $70-84 \%$ & 12 & 7.2 \\
\hline $55-69 \%$ & 64 & 39 \\
\hline$<55 \%$ & 86 & 52 \\
\hline No answer & 0 & 0.0 \\
\hline \multicolumn{3}{|l|}{ 6. Time to dependence } \\
\hline$<1$ week & 61 & 37 \\
\hline $1-2$ weeks & 35 & 21 \\
\hline 2 weeks-1 month & 28 & 17 \\
\hline$>1$ month & 28 & 17 \\
\hline No answer & 14 & 8.4 \\
\hline \multicolumn{3}{|c|}{ 7. Safety of using OTC pain medication x opioids } \\
\hline Yes & 59 & 36 \\
\hline No & 60 & 36 \\
\hline No answer & 47 & 28 \\
\hline \multicolumn{3}{|c|}{ 8. Comfort level with using naloxone } \\
\hline Extremely comfortable & 40 & 24 \\
\hline Somewhat comfortable & 26 & 16 \\
\hline Neutral & 68 & 41 \\
\hline Somewhat uncomfortable & 17 & 10 \\
\hline Extremely uncomfortable & 13 & 7.8 \\
\hline No answer & 2 & 1.2 \\
\hline
\end{tabular}


Table 2 (continued)

\begin{tabular}{|c|c|c|}
\hline \multicolumn{3}{|c|}{ Patient understanding regarding opioid use } \\
\hline Responses & $\begin{array}{l}\text { No. of } \\
\text { respondents }\end{array}$ & $\%^{\mathrm{a}}$ \\
\hline \multicolumn{3}{|c|}{ 9. Pain level (1-10) requiring opioid use } \\
\hline $0-2$ & 0 & 0.0 \\
\hline $3-4$ & 3 & 1.8 \\
\hline $5-6$ & 19 & 11 \\
\hline $7-8$ & 75 & 45 \\
\hline $9-10$ & 53 & 32 \\
\hline No answer & 16 & 9.6 \\
\hline \multicolumn{3}{|c|}{ 10. I can become addicted to opioids } \\
\hline Yes & 140 & 84 \\
\hline No & 19 & 11 \\
\hline No answer & 7 & 4.2 \\
\hline \multicolumn{3}{|c|}{ 11. Others can become addicted to opioids } \\
\hline Yes & 165 & 99 \\
\hline No & 0 & 0.0 \\
\hline No answer & 1 & 0.6 \\
\hline \multicolumn{3}{|c|}{ 12. Opioids can harm me } \\
\hline Yes & 159 & 96 \\
\hline No & 5 & 3.0 \\
\hline No answer & 2 & 1.2 \\
\hline \multicolumn{3}{|c|}{ 13. I know enough to take opioids safely } \\
\hline Yes & 143 & 86 \\
\hline No & 11 & 6.6 \\
\hline No answer & 12 & 7.2 \\
\hline
\end{tabular}

OTC, Over the counter

${ }^{\text {a }}$ Percentages may not add to 100 from rounding error

Our study illustrates that there are significant gaps in understanding and concerning patterns of beliefs regarding opioid use for orthopaedic trauma surgery patients, even amongst a predominantly high socioeconomic status population. While our respondents had a fairly strong recognition of common opioids, they had a poor understanding of side effects, withdrawal symptoms, and appropriate disposal methods. One potential explanation may be that commercial media has improved public recognition of common opioids, but awareness of their medical implications is still lacking [24, 25] This theory is further supported by our results illustrating greater identification of side effects, such as addiction (87\%) and constipation $(78 \%)$, that have received more media attention [26].

Our study demonstrates the need for additional education of all our patients in several areas. A subset of the respondents believe that they cannot become addicted to opioids, even when they recognize the addictive potential for others. This is consistent with the results of previous studies, which have shown inaccurate perception of individual risk may be due to addiction stigma or the perception that addiction is a moral failing that can be resisted through personal willpower [27-29]. Patients also lacked knowledge about the rapid nature of opioid dependence and naloxone use [30,31]. Patients had a better understanding of dependence and appropriate dosing, as over half of our patients understand that dependence can occur within 2 weeks and patients almost universally would not take an opioid for mild pain levels. This may demonstrate early successes with patient education on opioid use.

We found that race was independently associated with level of understanding, with patients identifying as white being significantly less likely to have discrepancy in addiction perception [32,33]. This may be attributed to an awareness that the most dramatic increase in overdose mortality in the last two decades occurred amongst nonHispanic whites [34, 35]. Much of the recent social and political attention on the opioid epidemic has also been focused on this population [36, 37]. While use amongst whites has been framed as a public health crisis, the media has traditionally portrayed blacks with opioid use disorders as having a moral shortcoming and undergoing greater criminalization [36]. Minorities thus may have alternative perceptions regarding opioid use and selfaddiction. However, our findings cannot be confidently interpreted without more robust quantitative studies that do not use race as a surrogate for other factors (i.e., health behaviours).

We further illustrated that employment with higher education level and being from the least disadvantaged ADI quartile were associated with lesser levels of knowledge regarding opioid use when controlling for potential confounders. This contrasts with the results of Bargon et al. [20], who demonstrated higher education to be associated with patients understanding the importance of opioid prescribing policies, suggesting greater knowledge of opioid misuse. This conflicting and limited evidence emphasizes the necessity for further studies evaluating patient knowledge of opioids in orthopaedic surgery. Our findings may reflect that patients of lower socioeconomic measures and from more disadvantaged geographic regions are more frequently exposed to opioid prescription, chronic consumption, and related overdose in their communities [38-41]. This exposure, in turn, may translate to greater knowledge regarding opioids.

In addition, patients had significantly greater levels of understanding if they were currently using opioids or knew someone who misused opioids. This aligns with 
Table 3 Adjusted (multivariable) odds of orthopaedic trauma surgery patient understanding regarding opioid use

\begin{tabular}{|c|c|c|c|c|c|c|c|c|c|}
\hline \multirow[t]{2}{*}{ Parameter } & $\begin{array}{l}>85 \% \\
\text { common } \\
\text { opioids }\end{array}$ & $\begin{array}{l}\text { Suboxone/ } \\
\text { subutex }\end{array}$ & $\begin{array}{l}>85 \% \\
\text { side } \\
\text { effects }\end{array}$ & $\begin{array}{l}>85 \% \\
\text { withdrawal } \\
\text { symptoms }\end{array}$ & Dependence $<2$ weeks & $\begin{array}{l}\text { OTC } x \\
\text { opioid } \\
\text { safety }\end{array}$ & $\begin{array}{l}\text { Comfort } \\
\text { with } \\
\text { naloxone }\end{array}$ & $\begin{array}{l}\text { Addiction } \\
\text { discrepancy }^{\mathrm{a}}\end{array}$ & $\begin{array}{l}\text { Know } \\
\text { enough to } \\
\text { take safely }\end{array}$ \\
\hline & \multicolumn{9}{|c|}{ Adjusted odds ratio $(95 \% \mathrm{Cl})$} \\
\hline \multicolumn{10}{|l|}{ Gender } \\
\hline Male ${ }^{b}$ & - & - & - & - & - & - & - & - & - \\
\hline Female & $\begin{array}{l}0.68 \\
(0.26-1.8)\end{array}$ & $\begin{array}{l}0.94 \\
(0.37-2.4)\end{array}$ & $\begin{array}{l}1.7 \\
(0.38-7.2)\end{array}$ & $\begin{array}{l}1.1 \\
(0.44-2.7)\end{array}$ & $2.0(0.76-5.2)$ & $\begin{array}{l}0.64 \\
(0.22-1.8)\end{array}$ & $\begin{array}{l}1.7 \\
(0.69-4.2)\end{array}$ & $0.88(0.25-3.1)$ & $1.8(0.28-11)$ \\
\hline \multicolumn{10}{|l|}{ Age } \\
\hline$<65$ years $^{\mathrm{b}}$ & - & - & - & - & - & - & - & - & - \\
\hline$\geq 65$ years & $\begin{array}{l}0.38 \\
(0.11-1.3)\end{array}$ & $\begin{array}{l}0.42 \\
(0.13-1.3)\end{array}$ & $\begin{array}{l}0.13 \\
(0.01-1.3)\end{array}$ & $\begin{array}{l}0.63 \\
(0.21-1.9)\end{array}$ & $1.3(0.45-4.0)$ & $\begin{array}{l}0.77 \\
(0.24-2.5)\end{array}$ & $\begin{array}{l}1.1 \\
(0.40-3.0)\end{array}$ & $1.2(0.31-4.3)$ & $\begin{array}{l}0.97 \\
(0.11-9.0)\end{array}$ \\
\hline \multicolumn{10}{|l|}{ Race } \\
\hline White ${ }^{b}$ & - & - & - & - & - & - & - & - & - \\
\hline Non-white & $\begin{array}{l}0.50 \\
(0.12-2.1)\end{array}$ & $\begin{array}{l}1.1 \\
(0.28-3.9)\end{array}$ & $\begin{array}{l}1.5 \\
(0.19-11)\end{array}$ & $\begin{array}{l}1.1 \\
(0.29-4.2)\end{array}$ & $0.45(0.13-1.6)$ & $\begin{array}{l}0.57 \\
(0.15-2.1)\end{array}$ & $\begin{array}{l}1.0 \\
(0.30-3.5)\end{array}$ & $7.8(1.9-31)^{* *}$ & 1.0 \\
\hline \multicolumn{10}{|c|}{ Marital status } \\
\hline Single $e^{b}$ & - & - & - & - & - & - & - & - & - \\
\hline Married & $\begin{array}{l}0.73 \\
(0.30-1.8)\end{array}$ & $\begin{array}{l}2.0 \\
(0.79-4.9)\end{array}$ & $\begin{array}{l}1.6 \\
(0.40-6.2)\end{array}$ & $\begin{array}{l}1.8 \\
(0.75-4.6)\end{array}$ & $1.9(0.79-4.8)$ & $\begin{array}{l}0.81 \\
(0.30-2.2)\end{array}$ & $\begin{array}{l}0.55 \\
(0.24-1.2)\end{array}$ & $1.1(0.35-3.5)$ & $2.7(0.41-17)$ \\
\hline \multicolumn{10}{|c|}{ Employment status stratified by education level } \\
\hline $\begin{array}{l}\text { Unem- } \\
\text { ployed }^{\text {b }}\end{array}$ & - & - & - & - & - & - & - & - & - \\
\hline $\begin{array}{l}\text { Employed } \\
\text { w/ } \\
<4-y r \\
\text { degree }\end{array}$ & $\begin{array}{l}1.1 \\
(0.37-3.1)\end{array}$ & $\begin{array}{l}0.85 \\
(0.30-2.4)\end{array}$ & $\begin{array}{l}0.67 \\
(0.16-2.8)\end{array}$ & $\begin{array}{l}0.53 \\
(0.19-1.5)\end{array}$ & $0.53(0.19-1.5)$ & $\begin{array}{l}1.4 \\
(0.46-4.1)\end{array}$ & $\begin{array}{l}1.5 \\
(0.58-3.8)\end{array}$ & $2.0(0.55-7.1)$ & $\begin{array}{l}0.53 \\
(0.06-4.5)\end{array}$ \\
\hline $\begin{array}{l}\text { Employed } \\
\text { w/ } \\
\geq 4-y r \\
\text { degree }\end{array}$ & $\begin{array}{l}1.6 \\
(0.55-4.6)\end{array}$ & $\begin{array}{l}1.6 \\
(0.55-4.4)\end{array}$ & $\begin{array}{l}0.06 \\
(0.006- \\
0.56)^{*}\end{array}$ & $\begin{array}{l}0.77 \\
(0.28-2.2)\end{array}$ & $0.28(0.09-0.86)^{*}$ & $\begin{array}{l}0.75 \\
(0.24-2.3)\end{array}$ & $\begin{array}{l}0.61 \\
(0.22-1.7)\end{array}$ & $0.73(0.16-3.4)$ & $1.1(0.07-17)$ \\
\hline \multicolumn{10}{|c|}{ ADI national quartile } \\
\hline $1^{b}$ & - & - & - & - & - & - & - & - & - \\
\hline 2 & $\begin{array}{l}0.79 \\
(0.28-2.2)\end{array}$ & $\begin{array}{l}2.3 \\
(0.86-6.4)\end{array}$ & $\begin{array}{l}8.8 \\
(1.7-46)^{* *}\end{array}$ & $\begin{array}{l}2.7 \\
(1.0-7.2)^{*}\end{array}$ & $1.2(0.43-3.5)$ & $\begin{array}{l}0.51 \\
(0.18-1.5)\end{array}$ & $\begin{array}{l}1.1 \\
(0.42-2.7)\end{array}$ & $1.1(0.32-4.1)$ & $\begin{array}{l}0.13 \\
(0.01-1.5)\end{array}$ \\
\hline $3+4$ & $\begin{array}{l}0.66 \\
(0.21-2.0)\end{array}$ & $\begin{array}{l}1.9 \\
(0.62-5.6)\end{array}$ & $\begin{array}{l}6.1 \\
(0.95-39)\end{array}$ & $\begin{array}{l}1.5 \\
(0.49-4.4)\end{array}$ & $1.1(0.35-3.3)$ & $\begin{array}{l}0.53 \\
(0.16-1.8)\end{array}$ & $\begin{array}{l}0.65 \\
(0.23-1.9)\end{array}$ & $0.72(0.15-3.4)$ & $\begin{array}{l}0.41 \\
(0.02-8.0)\end{array}$ \\
\hline \multicolumn{10}{|c|}{ Chronicity of injury } \\
\hline $\begin{array}{l}\text { Acute or } \\
\text { subacute }^{b}\end{array}$ & - & - & - & - & - & - & - & - & - \\
\hline Chronic & $\begin{array}{l}2.5 \\
(0.79-8.0)\end{array}$ & $\begin{array}{l}1.3 \\
(0.42-4.0)\end{array}$ & $\begin{array}{l}0.23 \\
(0.03-1.6)\end{array}$ & $\begin{array}{l}0.51 \\
(0.15-1.7)\end{array}$ & $1.0(0.31-3.4)$ & $\begin{array}{l}0.49 \\
(0.14-1.7)\end{array}$ & $\begin{array}{l}2.6 \\
(0.89-7.9)\end{array}$ & $2.7(0.67-11)$ & 1.0 \\
\hline \multicolumn{10}{|c|}{ Prior opioid prescription } \\
\hline $\mathrm{No}^{\mathrm{b}}$ & - & - & - & - & - & - & - & - & - \\
\hline Yes & 1.0 & 1.0 & 1.0 & 1.0 & 1.0 & 1.0 & 1.0 & 1.0 & 1.0 \\
\hline \multicolumn{10}{|c|}{ Current opioid use } \\
\hline $\mathrm{No}^{\mathrm{b}}$ & - & - & - & - & - & - & - & - & - \\
\hline Yes & $\begin{array}{l}1.9 \\
(0.47-8.0)\end{array}$ & $\begin{array}{l}0.66 \\
(0.15-2.9)\end{array}$ & $\begin{array}{l}1.9 \\
(0.47-8.0)\end{array}$ & $\begin{array}{l}0.27 \\
(0.05-1.6)\end{array}$ & $0.61(0.14-2.6)$ & $\begin{array}{l}5.2 \\
(1.0-27)^{*}\end{array}$ & $\begin{array}{l}1.5 \\
(0.35-6.2)\end{array}$ & $0.97(0.16-6.0)$ & 1.0 \\
\hline \multicolumn{10}{|c|}{ Prior naloxone prescription } \\
\hline $\mathrm{No}^{\mathrm{b}}$ & - & - & - & - & - & - & - & - & - \\
\hline Yes & $\begin{array}{l}1.3 \\
(0.31-5.2)\end{array}$ & $\begin{array}{l}1.3 \\
(0.31-5.1)\end{array}$ & $\begin{array}{l}1.3 \\
(0.31-5.2)\end{array}$ & $\begin{array}{l}0.73 \\
(0.16-3.3)\end{array}$ & $0.90(0.23-3.5)$ & $\begin{array}{l}1.8 \\
(0.42-7.9)\end{array}$ & $\begin{array}{l}1.8 \\
(0.48-6.9)\end{array}$ & $0.82(0.13-5.2)$ & 1.0 \\
\hline \multicolumn{10}{|c|}{ Know someone dependent/overdosed } \\
\hline $\mathrm{No}^{\mathrm{b}}$ & - & - & - & - & - & - & - & - & - \\
\hline
\end{tabular}


Table 3 (continued)

\begin{tabular}{|c|c|c|c|c|c|c|c|c|c|}
\hline \multirow[t]{2}{*}{ Parameter } & $\begin{array}{l}>85 \% \\
\text { common } \\
\text { opioids }\end{array}$ & $\begin{array}{l}\text { Suboxone/ } \\
\text { subutex }\end{array}$ & $\begin{array}{l}>85 \% \\
\text { side } \\
\text { effects }\end{array}$ & $\begin{array}{l}>85 \% \\
\text { withdrawal } \\
\text { symptoms }\end{array}$ & Dependence $<2$ weeks & $\begin{array}{l}\text { OTC } x \\
\text { opioid } \\
\text { safety }\end{array}$ & $\begin{array}{l}\text { Comfort } \\
\text { with } \\
\text { naloxone }\end{array}$ & $\begin{array}{l}\text { Addiction } \\
\text { discrepancy }^{\text {a }}\end{array}$ & $\begin{array}{l}\text { Know } \\
\text { enough to } \\
\text { take safely }\end{array}$ \\
\hline & \multicolumn{9}{|c|}{ Adjusted odds ratio $(95 \% \mathrm{Cl})$} \\
\hline Yes & $\begin{array}{l}1.9 \\
(0.74-5.0)\end{array}$ & $\begin{array}{l}2.2 \\
(0.88-5.7)\end{array}$ & $\begin{array}{l}1.9 \\
(0.74-5.0)\end{array}$ & $\begin{array}{l}2.6 \\
(1.1-6.5)^{*}\end{array}$ & $3.8(1.5-9.8)^{* *}$ & $\begin{array}{l}0.78 \\
(0.29-2.1)\end{array}$ & $\begin{array}{l}1.5 \\
(0.66-3.5)\end{array}$ & $\begin{array}{l}0.24(0.07- \\
0.76)^{*}\end{array}$ & $1.8(0.26-1$ \\
\hline
\end{tabular}

Bold values indicate significant associations between patient characteristics and measures of understanding regarding opioid use

OTC, Over the counter; ADI, area deprivation index

*Significant at $p<0.05$

**Significant at $p<0.01$

*** Significant at $p<0.001$

${ }^{\text {a }}$ Addiction discrepancy $=$ patients who believed that others, but not self, can become addicted to opioids

${ }^{\mathrm{b}}$ Referent

the results of Razdan et al., who determined that knowledge regarding opioid use for paediatric patients was greater for parents who knew someone who had become addicted to opioids [42]. Stover et al. [43] also demonstrated that young adults who received prior naloxone training or opioid prescriptions scored significantly higher on the Opioid Overdose Knowledge Scale. It is possible that these patients were educated by their prescribing physician or distributing pharmacist on the appropriate use and risks involved. Another plausible explanation is that in light of the ongoing opioid epidemic, patients were more aware of the intrinsic risks and more inclined to research these risks upon receiving prescriptions or having someone they know become dependent or overdosing on opioids [43]. Recent initiatives to educate patients through counseling and public materials thus may be effective, and it is important for surgeons to follow recommendations for co-prescription of naloxone and opioids. Altogether, these results suggest that clinical and personal experience with opioids should be emphasized when taking patient histories, and those with positive histories may be more knowledgeable in the appropriate use and risks of taking prescription opioids in the postoperative period.

Our study is not without limitations. The electronic format of our survey distribution was a result of the COVID19 pandemic, which restricted access to patient care areas (i.e. trauma clinics). Subsequently, the study was limited by responder bias with the low response rate. Responders likely differ from non-responders, especially since the survey's electronic format tends to attract more white responders possessing higher socioeconomic measures [44, 45]. As a result, the respondents did not accurately represent the trauma patient population seen by our institution, which serves a clinically diverse, minority-majority patient population within an urban environment. However, it must be noted that the response rate was based on the 2352 patients who opened the survey invitation, thereby controlling for internet access and associated socioeconomics to an extent. Respondents also likely had more personal experiences with opioids which motivated them to answer the survey. Despite the high socioeconomic measures of our cohort, we were able to capture 17 unique individuals $(10 \%)$ who reported self-dependency or overdose on opioids, which is higher than the estimated national rate of prescription opioid misuse (3.6\%) amongst people aged 12 years or older [46]. Overall, our respondent characteristics would trend toward greater awareness of opioids and the importance of understanding their appropriate use [20, 43], so the low level of understanding in our results likely overestimates opioid knowledge, emphasizing the importance of presenting our findings.

\section{Conclusions}

In conclusion, all prescribers should be aware that there is a low level of understanding regarding opioid use in patients who present to orthopaedic trauma surgery clinics. This places patients at higher risk for misusing opioids if prescribed. It is essential to emphasize that providers should not exacerbate existing prescribing disparities and reduce access to opioids for patients with lesser understanding. Rather, more involved educational interventions should be taken with these patients to mediate risk for misuse, and improvements in overall patient education should be established at all institutions. To more comprehensively study patient understanding, future studies should apply larger scale, multidisciplinary, multicenter surveys and investigate the effectiveness of specific educational interventions in improving patient knowledge. Application of robust qualitative methods grounded in well-established social theories, like the Health Belief Model, which is outside the scope of this study, would be better able to provide reasons behind the perceptions assessed here as well. 


\section{Appendix}

Survey on trauma patient knowledge and perspectives about opioids

Medication knowledge

(1) An opioid is a specific type of prescribed pain medication. Which of the following which are opioids? Select all that apply.

(a) Ibuprofen, (b) Aspirin, (c) Morphine, (d) Methadone, (e) Codeine, (f) Oxycodone, (g) Hydrocodone, (h) Hydromorphone, (i) Oxycontin, (j) Percocet, (k) Dilaudid, (l) Tylenol \#3, (m) Gabapentin, (n) Fentanyl, (o) Heroin, (p) Tramadol, (q) Caffeine, (r) Steroids, (s) Buprenorphine, (t) Naloxone, (u) Subutex, (v) Suboxone

(2) Side effects are undesirable effects of a drug or treatment. Which of the following are side effects of taking opioids? Select all that apply.

(a) Constipation, (b) Nausea, (c) Fatigue, (d) Mental fog, (e) Liver failure, (f) Dizziness, (g) Gastrointestinal bleeding, (h) Vomiting, (i) Trouble breathing, (j) Skin rash, (k) Increased pain, (l) Depression, (m) Addiction, (n) Cancer, (o) Death

(3) Opioid withdrawal is when a person experiences discomfort when a medication is no longer taken regularly. Which of the following are signs/symptoms of opioid withdrawal? Select all that apply.

(a) Paranoia, (b) Nausea, (c) Depression, (d) Chills, (e) Tremors, (f) Sweating, (g) Itching, (h) Constipation, (i) Poor coordination, (j) Restlessness, (k) Anxiety

(4) Dependence is the body's physical and mental need for continued opioid use. How long do you think it takes to develop opioid dependence?

(a) Less than 1 week, (b) More than 1 week but less than 2 weeks, (c) More than 2 weeks but less than 1 month, (d) More than 1 month but less than 3 months, (e) More than 3 months but less than 6 months, (f) More than 6 months, (g) Other

(5) Is it safe to take over-the-counter pain medications at the same time as an opioid?

(a) Yes, (b) No, (c) Don't know

(6) What are acceptable ways to dispose of unused opioid pain medications? Select all that apply.

(a) Pour it down the sink, (b) Flush it down the toilet, (c) Throw away pills in household trash, (d) Return to the police, (e) Return to the pharmacy, (f) Return to a "take back" program, (g) Keep it for future use for self, (h) Keep for future use of a family member or friend, (i) Other

\section{Personal experience}

(7) Do you know or have you known someone who had ever been dependent on prescribed pain medication?

(a) No, (b) Self, (c) Partner, (d) Family member,

(e) Friend, (f) Other, (g) Don't know

(8) Do you know or have you known someone who had ever had an overdose from prescribed pain medication or a pain medication obtained through other means?

(a) No, (b) Self, (c) Partner, (d) Family member,

(e) Friend, (f) Other, (g) Don't know

(9) How comfortable are you with using naloxone in the event of an overdose?

(a) Extremely comfortable, (b) Somewhat comfortable, (c) Neither comfortable nor uncomfortable, (d) Somewhat uncomfortable, (e) Extremely uncomfortable

(10) Have you had a prior surgery?

(a) Yes, (b) No

(11) Have you ever been prescribed medication for pain?

(a) Yes, (b) No, (c) Don't know

(12) [If "yes" to 11] Have you ever been prescribed an opioid medication for pain?

(a) Yes, (b) No, (c) Don't know

(13) [If "yes" to 12] Are you currently taking an opioid medication for pain?

(a) Yes, (b) No, (c) Don't know

(14) [If "yes" to 12] Have you ever been prescribed naloxone to use in the event of an overdose?

(a) Yes, (b) No, (c) Don't know

(15) [If "yes" to 12] Did you receive instructions on proper opioid disposal with your prescription?

(a) Yes, (b) No, (c) Don't know

\section{Beliefs and perspectives}

(16) Do you think that opioids can harm you?

(a) Yes, (b) No, (c) Don't know

(17) Do you think that you can get addicted to taking opioids?
(a) Yes, (b) No, (c) Don't know

(18) Do you think that other people can get addicted to taking opioids?

(a) Yes, (b) No, (c) Don't know

(19) At what level of pain would you take an opioid for pain control on a scale of $0-10$, with 0 meaning no pain and 10 meaning the worst pain?

[respond on $0-10$ scale] 
(20) Do you think you know what you need to take opioids safely?

(a) Yes, (b) No, (c) Don't know

(21) Would you appreciate more information on opioids?
(a) Yes, (b) No

(22) What are 1-5 words that come to mind when you think about opioids?

[open response]

(23) What else should we know? Please do NOT include any information which could be used to identify you.

[open response]

\section{Patient characteristics}

(24) Gender
(a) Male, (b) Female, (c) Other

(25) Age (years)

(a) Under 18, (b) 18-24, (c) 25-34, (d) 35-44, (e) 45-54, (f) 55-64, (g) 65-74, (h) 75-84, (i) 85 or older

(26) Race/ethnicity

(a) White, (b) Black or African American, (c) Hispanic or Latino, (d) Asian, (e) American Indian or Native Alaskan, (f) Native Hawaiian or Pacific Islander, (g) Other

(27) Insurance status

(a) Insured, (b) Uninsured, (c) Don't know

(28) Employment

(a) Employed full time, (b) Employed part time,

(c) Unemployed looking for work, (d) Unemployed not looking for work, (e) Retired, (f) Student, (g) Disabled

(29) Marital status

(a) Married, (b) Widowed, (c) Divorced, (d) Separated, (e) Never married

(30) Zip code

[open response]

(31) Highest level of education

(a) Less than high school, (b) High school graduate, (c) Some college, (d) 2-year degree, (e) 4-year degree, (f) Professional degree, g) Doctorate

(32) Reason for clinic visit

(a) Injury/accident/problem that started less than 2 weeks ago, (b) Injury/accident/problem that started more than 2 weeks ago, (c) Chronic problem/pain for at least a year

\section{Abbreviations}

COVID-19: Coronavirus disease; ADI: Area deprivation index; OTC: Over the counter.

\section{Supplementary Information}

The online version contains supplementary material available at https://doi. org/10.1186/s13018-021-02881-w.

Additional file 1. Unadjusted (univariate) odds of orthopaedic trauma surgery patient understanding regarding opioid use.

\section{Acknowledgements}

Not applicable.

\section{Authors' contributions}

ALX contributed to survey design, data analysis and interpretation, and primary draft of the manuscript. AMD contributed to study and survey design, survey administration, and critical revisions of manuscript. ZOE contributed to data analysis and interpretation, critical revisions of manuscript. CJH contributed to study and survey design, critical revisions of manuscript. All authors read and approved the final manuscript.

\section{Funding}

One or more of the authors (AMD, ZOE) received funding from the National Institutes of Health (Grant T32 AR067708)

\section{Availability of data and materials}

The datasets used and/or analysed during the current study are available from the corresponding author on reasonable request.

\section{Declarations}

Ethics approval and consent to participate

This study was approved by The Johns Hopkins Institutional Review Board (IRB00243659). Consent was obtained from all participants before administration of the survey.

\section{Consent for publication}

Not applicable.

\section{Competing interests}

The authors declare that they have no competing interests.

\section{Author details}

${ }^{1}$ Department of Orthopaedic Surgery, Johns Hopkins Hospital, Baltimore, MD, USA. ${ }^{2}$ Department of Surgery, Johns Hopkins Hospital, Baltimore, MD, USA

${ }^{3}$ Department of Orthopaedic Surgery, The University of Pennsylvania, 230 West Washington Square, 5th Floor Farm Journal Building „P Philadelphia, PA 19106, USA.

Received: 10 October 2021 Accepted: 6 December 2021

Published online: 24 December 2021

\section{References}

1. Opioid Overdose: Understanding the Epidemic. Centers for Disease Control and Prevention. Published 2020. https://www.cdc.gov/drugoverdose/ epidemic/index.html

2. Alam A, Gomes T, Zheng H, Mamdani MM, Juurlink DN, Bell CM. Longterm analgesic use after low-risk surgery: a retrospective cohort study. Arch Intern Med. 2012;172(5):425-30. https://doi.org/10.1001/archintern med.2011.1827.

3. Clarke H, Soneji N, Ko DT, Yun L, Wijeysundera DN. Rates and risk factors for prolonged opioid use after major surgery: population based cohort study. BMJ. 2014;348: g1251. https://doi.org/10.1136/bmj.g1251.

4. Howard R, Waljee J, Brummett C, Englesbe M, Lee J. Reduction in opioid prescribing through evidence-based prescribing guidelines. JAMA Surg 2018;153(3):285-7. https://doi.org/10.1001/jamasurg.2017.4436.

5. Hill MV, Stucke RS, McMahon ML, Beeman JL, Barth RJ. An educational intervention decreases opioid prescribing after general surgical 
operations. Ann Surg. 2018;267(3):468-72. https://doi.org/10.1097/SLA. 0000000000002198.

6. Overdose Deaths Accelerating During COVID-19: Expanded Prevention Efforts Needed. Centers for Disease Control and Prevention. Published 2020. https://www.cdc.gov/media/releases/2020/p1218-overdosedeaths-covid-19.html

7. Koehler RM, Okoroafor UC, Cannada LK. A systematic review of opioid use after extremity trauma in orthopedic surgery. Injury. 2018:49(6):1003-7. https://doi.org/10.1016/j.injury.2018.04.003.

8. Pagé MG, Kudrina I, Zomahoun HTV, et al. Relative frequency and risk factors for long-term opioid therapy following surgery and trauma among adults: a systematic review protocol. Syst Rev. 2018;7(1):97. https://doi.org/10.1186/s13643-018-0760-3.

9. Johnson SP, Chung KC, Zhong L, et al. Risk of prolonged opioid use among opioid-naîve patients following common hand surgery procedures. J Hand Surg. 2016;41(10):947-957.e3. https://doi.org/10.1016/j. jhsa.2016.07.113.

10. Mohamadi A, Chan JJ, Lian J, et al. Risk factors and pooled rate of prolonged opioid use following trauma or surgery: a systematic review and meta-(regression) analysis. J Bone Joint Surg Am. 2018;100(15):1332-40. https://doi.org/10.2106/JBJS.17.01239.

11. Holman JE, Stoddard GJ, Higgins TF. Rates of prescription opiate use before and after injury in patients with orthopaedic trauma and the risk factors for prolonged opiate use. J Bone Joint Surg Am. 2013;95(12):1075-80. https://doi.org/10.2106/JBJS.L.00619.

12. Daoust $R$, Paquet J, Moore $L$, et al. Incidence and risk factors of longterm opioid use in elderly trauma patients. Ann Surg. 2018;268(6):98591. https://doi.org/10.1097/SLA.0000000000002461.

13. Yorkgitis BK, Raygor D, Bryant E, Brat G, Smink DS, Crandall M. Surgery program directors' knowledge of opioid prescribing regulations: a survey study. J Surg Res. 2018;227:194-7. https://doi.org/10.1016/j.jss. 2018.02.036.

14. Madsen AM, Stark LM, Has P, Emerson JB, Schulkin J, Matteson KA Opioid knowledge and prescribing practices among obstetriciangynecologists. Obstet Gynecol. 2018;131(1):150-7. https://doi.org/10. 1097/AOG.0000000000002407.

15. Hooten WM, Dvorkin J, Warner NS, Pearson AC, Murad MH, Warner DO. Characteristics of physicians who prescribe opioids for chronic pain: a meta-narrative systematic review. J Pain Res. 2019;12:2261-89. https:// doi.org/10.2147/JPR.S202376

16. Soffin EM, Waldman SA, Stack RJ, Liguori GA. An evidence-based approach to the prescription opioid epidemic in orthopedic surgery. Anesth Analg. 2017;125(5):1704-13. https://doi.org/10.1213/ANE.00000 00000002433.

17. de la Cruz M, Reddy A, Balankari V, et al. The impact of an educational program on patient practices for safe use, storage, and disposal of opioids at a comprehensive cancer center. Oncologist. 2017;22(1):115-21. https://doi.org/10.1634/theoncologist.2016-0266.

18. Nielsen S, Peacock A, Lintzeris N, Bruno R, Larance B, Degenhardt L. Knowledge of opioid overdose and attitudes to supply of take-home naloxone among people with chronic noncancer pain prescribed opioids. Pain Med Malden Mass. 2018;19(3):533-40. https://doi.org/10. 1093/pm/pnx021.

19. Dunn KE, Barrett FS, Yepez-Laubach C, et al. Brief opioid overdose knowledge (book): a questionnaire to assess overdose knowledge in individuals who use illicit or prescribed opioids. J Addict Med. 2016;10(5):314-23. https://doi.org/10.1097/ADM.0000000000000235.

20. Bargon CA, Zale EL, Magidson J, Chen N, Ring D, Vranceanu AM. Factors associated with patients' perceived importance of opioid prescribing policies in an orthopedic hand surgery practice. J Hand Surg. 2019;44(4):340.e1-340.e8. https://doi.org/10.1016/j.jhsa.2018.06.118.

21. Prince LY, Mears SC, Watson JC, Hadden KB. Health literacy evaluation of opioid patient education materials for orthopaedic surgery. J Surg Orthop Adv. 2019;28(3):232-6.

22. Hadden KB, Prince LY, Barnes CL. Health literacy and opioid use in orthopaedic patients. J Surg Orthop Adv. 2016;25(4):234-7.

23. University of Wisconsin School of Medicine and Public Health. Neighborhood Atlas. Published 2018. https://www.neighborhoodatlas.medic ine.wisc.edu/
24. Webster F, Rice K, Sud A. A critical content analysis of media reporting on opioids: The social construction of an epidemic. Soc Sci Med. 1982;2020(244):112642. https://doi.org/10.1016/j.socscimed.2019.112642.

25. Kim CL, Hong SJ, Lim YH, et al. Patients' perception about opioids and addiction in South Korea. Korean J Pain. 2020;33(3):234-44. https://doi. org/10.3344/kjp.2020.33.3.234

26. Kroll D. OICisDifferent: the drug behind the super bowl 50 Constipation Ad. Forbes. Published 2016. https://www.forbes.com/sites/davidkroll/ 2016/02/09/oicisdifferent-the-drug-behind-the-super-bowl-50-constipati on-ad/?sh=d1e0b6d52133

27. Wood E, Elliott M. Opioid addiction stigma: the intersection of race, social class, and gender. Subst Use Misuse. 2020;55(5):818-27. https://doi.org/ 10.1080/10826084.2019.1703750

28. Tsai AC, Kiang MV, Barnett ML, et al. Stigma as a fundamental hindrance to the United States opioid overdose crisis response. PLoS Med. 2019;16(11):e1002969. https://doi.org/10.1371/journal.pmed.1002969.

29. Olsen Y, Sharfstein JM. Confronting the stigma of opioid use disorderand its treatment. JAMA. 2014;311(14):1393-4. https://doi.org/10.1001/ jama.2014.2147.

30. Brady KT, McCauley JL, Back SE. Prescription opioid misuse, abuse, and treatment in the United States: an update. Am J Psychiatry. 2016;173(1):18-26. https://doi.org/10.1176/appi.ajp.2015.15020262.

31. Shah A, Hayes CJ, Martin BC. Characteristics of initial prescription episodes and likelihood of long-term opioid use-United States, 2006-2015. MMWR Morb Mortal Wkly Rep. 2017;66(10):265-9. https://doi.org/10. 15585/mmwr.mm6610a1.

32. Reinberg $\mathrm{S}$. Opioid dependence can start in just a few days. WedMD. Published 2017. https://www.webmd.com/mental-health/addiction/ news/20170316/opioid-dependence-can-start-in-just-a-few-days\%232\#1

33. Dowell D, Haegerich TM, Chou R. CDC Guideline for Prescribing Opioids for Chronic Pain_United States, 2016. Centers for Disease Control and Prevention. Published 2016. https://www.cdc.gov/mmwr/volumes/65/rr/ rr6501e1.htm

34. Singh GK, Kim IE, Girmay M, et al. Opioid epidemic in the united states: empirical trends, and a literature review of social determinants and epidemiological, pain management, and treatment patterns. Int J MCH AIDS 2019;8(2):89-100. https://doi.org/10.21106/ijma.284.

35. Hudgins JD, Porter JJ, Monuteaux MC, Bourgeois FT. Prescription opioid use and misuse among adolescents and young adults in the United States: a national survey study. PLoS Med. 2019;16(11): e1002922. https:// doi.org/10.1371/journal.pmed.1002922.

36. James K, Jordan A. The opioid crisis in black communities. J Law Med Ethics J Am Soc Law Med Ethics. 2018;46(2):404-21. https://doi.org/10.1177/ 1073110518782949.

37. Netherland J, Hansen HB. The war on drugs that wasn't: wasted whiteness, "dirty doctors", and race in media coverage of prescription opioid misuse. Cult Med Psychiatry. 2016;40(4):664-86. https://doi.org/10.1007/ s1 1013-016-9496-5.

38. Kurani S, McCoy RG, Inselman J, et al. Place, poverty and prescriptions: a cross-sectional study using area deprivation index to assess opioid use and drug-poisoning mortality in the USA from 2012 to 2017. BMJ Open 2020;10(5):e035376. https://doi.org/10.1136/bmjopen-2019-035376.

39. Cheng AL, Brady BK, Bradley EC, et al. Opioid use and social disadvantage in patients with chronic musculoskeletal pain. PM R. 2021. https://doi. org/10.1002/pmri.12596.

40. Rhon DI, Snodgrass SJ, Cleland JA, Sissel CD, Cook CE. Predictors of chronic prescription opioid use after orthopedic surgery: derivation of a clinical prediction rule. Perioper Med Lond Engl. 2018;7:25. https://doi. org/10.1186/s13741-018-0105-8.

41. Galea S, Ahern J, Vlahov D, et al. Income distribution and risk of fatal drug overdose in New York City neighborhoods. Drug Alcohol Depend. 2003;70(2):139-48. https://doi.org/10.1016/s0376-8716(02)00342-3.

42. Razdan R, Stevens L, Ritchie M, Kennedy T, Carr MM. Parents' attitudes toward post-operative narcotic use in pediatric patients. Int J Pediatr Otorhinolaryngol. 2019;124:173-8. https://doi.org/10.1016/j.ijporl.2019. 06.006 .

43. Stover AN, Grogg K, Patel J, Thornton D, Dwibedi N. Opioid overdose knowledge among college students in a high overdose death state. J Hum Behav Soc Environ. 2019;29(7):887-96. https://doi.org/10.1080/ 10911359.2019.1633981. 
44. Hagan TL, Belcher SM, Donovan HS. Mind the mode: differences in paper vs. web-based survey modes among women with cancer. J Pain Symptom Manag. 2017;54(3):368-75. https://doi.org/10.1016/j.jpainsymman. 2017.07.005.

45. Zuidgeest M, Hendriks M, Koopman L, Spreeuwenberg P, Rademakers J. A comparison of a postal survey and mixed-mode survey using a questionnaire on patients' experiences with breast care. J Med Internet Res. 2011;13(3):e68. https://doi.org/10.2196/jmir.1241.

46. Center for Behavioral Health Statistics and Quality. Key Substance Use and Mental Health Indicators in the United States: Results from the 2019 National Survey on Drug Use and Health. https://www.samhsa.gov/data/ sites/default/files/reports/rpt29393/2019NSDUHFFRPDFWHTML/2019N SDUHFFR1PDFW090120.pdf. Accessed 28 Nov 2021

\section{Publisher's Note}

Springer Nature remains neutral with regard to jurisdictional claims in published maps and institutional affiliations.

- fast, convenient online submission

- thorough peer review by experienced researchers in your field

- rapid publication on acceptance

- support for research data, including large and complex data types

- gold Open Access which fosters wider collaboration and increased citations

- maximum visibility for your research: over $100 \mathrm{M}$ website views per year

At BMC, research is always in progress.

Learn more biomedcentral.com/submissions 